\title{
Understanding the acceptance of market-based instruments for the ecosystem service of water quality
}

\author{
G. L. Kerr ${ }^{1} \&$ H. Bjornlund ${ }^{2}$ \\ ${ }^{1}$ University of Calgary, Alberta, Canada \\ ${ }^{2}$ University of Lethbridge, Alberta, Canada and \\ University of South Australia, Australia
}

\begin{abstract}
Non point source (NPS) contamination in southern Alberta's agricultural belt is a known issue. While point source contamination is clearly regulated and managed the mandate and responsibility for dealing with NPS water quality issues appears unclear and overlapping. Market-based instruments (MBIs) are being promoted in Alberta as a tool to help meet environmental management goals.

This paper explores the role legitimacy, accountability and fit of MBIs based on two sets of semi-structured interviews, conducted to provide the background, context and perceptions around MBIs for water quality. One set of interviews focused on experts in the area of developing, implementing or analyzing MBIs for environmental objectives. The second set of interviews focused on local subject matter experts and knowledgeable stakeholders in the case study areas in southern Alberta.

Initial results indicate that while MBIs could have an important role in delivering better water quality outcomes, the issues of fit, accountability and legitimacy need to be addressed in the MBI design process. Currently these are not adequately addressed in the Alberta context MBIs are relatively new tools for environmental management. Q methodology will be employed to further expose the values orientations and perspectives.

Keywords: market-based instruments, non-point source contamination, water quality, accountability, legitimacy, fit.
\end{abstract}




\section{Introduction}

Governments globally are struggling to reverse negative trends of decreased ecosystem function. Due to their nature as landscape drainage 'sinks', aquatic ecosystems are particularly in jeopardy of overloading and contamination from both point and non-point sources (NPS). These water resources are critical to human well-being and therefore require purposeful attention to find sustainable and appropriate solutions. Scientist, social scientists and policy makers have been searching for mechanisms to change the negative trends with limited success.

Traditional management prescriptions often assume that ecosystem processes are understood, when in fact these complex environment-human relationships are one of continual change and uncertainty [1]. Most natural resources, aquatic and land management problems today defy traditional bureaucratic and analytic approaches to problem solving because these are complex, non-linear and uncertain [2]. Additionally, these problems have a diversity of values at stake, often conflicting [3]. Social-ecological systems theory, proposed by the Resilience Alliance, is a framework for looking at these complex and wicked environmental issues. However, as individual disciplines provide only partial answers, the question turns to how an interdisciplinary approach can be used to inform sustainable and appropriate solutions?

Non point source contamination of water in southern Alberta's agricultural belt is a well known issue [4]. While point source contamination is regulated and explicitly managed, the accountability and responsibility for dealing with NPS water quality issues appears unclear and overlapping amongst different government departments and actors. Market-based instruments (MBIs) are being promoted in Alberta as a tool to help meet environmental management goals. For the purposes of this paper, it is assumed that MBIs do have a role as a tool in the toolbox for governments to use to address environmental issues.

"Prescriptions need to fit contexts" [5]. Context is defined as the complex characteristics that distinguish one geographic and temporal place from another and signifies the nexus of physical, natural, political, cultural, social, and economic phenomena that make one place distinct from another [6]. Within this research it is critical to understand if MBIs will fit into the Alberta context, community and institutional arrangements. To ensure fit, policy design will therefore need to consider the values and perspectives of those to which the policy will be applied. In the absence of these considerations there is a potential risk that the 'prescription' will not achieve the intended results. However, taking this step of developing the context has been largely ignored in watershed and aquatic ecosystem management [7].

The target audience for the research results is government. The emphasis is on developing policy relevant outcomes and analysis to increase the success of well developed and theoretically sounds MBIs to support environmental management. The overarching principle that informs this research is that of Social-ecological systems. In the past policy and decision-making have separated the ecosystem from people. Some of the key issues with this are that the place- 
based context is not explicitly incorporated into the assessment and design on MBIs in Canada and, as a consequence, the individual values and perspectives held by stakeholders and the community are not incorporated into economic theory design principals. These are gaps that can have negative consequences on the ability to build effective management solutions, including the effective use of MBIs.

Society and nature must be brought together, including an acknowledgement and understanding of the values and subjectivity held by actors. It is hypothesized that with a Social-ecological system and contextual view coupled with a focus on understanding and incorporating value perspectives into MBI design, the acceptance of MBIs and therefore success will be greater.

\section{Research context}

The theoretical underpinnings of the research are interdisciplinary and intentionally draw form a number of schools of thought. When looking at MBIs the first place to look is economics and for this research there was a particular reliance on the emerging disciplines of political and institutional economics. Political economy refers to interdisciplinary studies drawing upon economics, law and political science in explaining how government institutions, the political environment, and the economic system influence each other. Institutional economics counters neo-classical economic assumption that we live in a world of rationality where institutions are unnecessary. Institutional economics recognizes that institutions play a critical role focusing on ideas and ideologies that impact society and the economy [8]. The institutional analysis provides a blueprint of what the governance landscape looks like and what the rules of engagement are or should be. Finally the research draws from the theory of Social-ecological systems that frames our world and the environmental challenges we face, on the human - environment interface. Ultimately this research recognizes that science and social science disciplines must be looked at as a whole for their contribution.

The research focuses on issues of acceptance of MBIs and therefore assumes that MBIs do have a place in environmental management. Specifically this research is looking at the issues of fit, accountability and legitimacy for MBIs. It is unique in that it builds on the theoretical learning's described above and focuses on the community and context in which MBIs will be designed. There is both an interdisciplinary lens through which the problem is viewed and a focus on the subjective values and perspectives of the key players: potential buyers and sellers of the ecosystem services produced by an MBI and the community at large, as the context onto which a tool is designed is crucial.

Accountability is the acknowledgement and execution of responsibility in a manner transparent to those affected. Legitimacy is achieved if the if those affected by the MBI approves of the institutions and/or actors designing and implementing the MBI and believes the process to be acceptable. Without legitimacy there will be unwillingness by the public to believe and participate in the approach or mechanism. Without clear accountability there is uncertainty and this leads to a lack of legitimacy and trust in the approach [9]. 


\subsection{Market-based instruments}

Market-based instruments use price signals to incentivize behaviours, either by using a carrot (such as a payment for service) or a stick (such as a tax or penalty for non-compliance). Governments use MBIs to influence private behaviour of the individuals by incentivizing 'rational men' toward a desired behaviour or penalties for poor behaviour [10]. (One of the key assumptions of modern economics is that humans behave rationally following wealth maximization principles.) Market-based instruments allow actors to make decisions based upon their own particular circumstances, preferences, attitudes and beliefs as applied to the particular context that they operate within. Traditionally the opportunity and role of MBIs has mainly been promoted by economists. This research proposes that a gap exists in our understanding of how to successfully develop and implement MBIs.

Despite these apparent benefits from using market-based instruments, there are few full scale/ non pilot examples in Canada. Analysts have listed a number of reasons for this, including political interference, lack of capacity, incomplete science to support the MBI and so on. However there is a largely unexplored area of understanding how values and perspectives influence the behaviour and decisions of individuals and groups that are impacted by or engaged in MBIs potential buyers and sellers of ecosystem services and the community in which the MBI is employed for a societal goal. Values are informed by culture, life cycle stage, socio-economics, place, perceptions and feelings. Individuals' values help to form the mental model they apply to understand what they experience. Lessons from institutional economics include that everyone has their own unique way of interpreting the world, which makes it difficult to predict human responses to policy change, including the implementation of a new MBI [8].

\section{Case study area and issue}

\subsection{Water Management}

The southern region of Alberta suffers from severe impacts on its aquatic ecosystems. In 2003, the Government of Alberta undertook studies to understand aquatic ecosystem needs in order to inform the South Saskatchewan River Basin (SSRB) planning process. One study found that 31 of 33 main stem rivers in the SSRB ranged from 'moderately impacted' to degraded [11]. A number of scientific studies have been completed to assess the level and type of contamination is southern Alberta's rivers, such as the prevalence on e-coli, nitrogen and phosphorous [12].

Accountability for water quality is not clear to all stakeholders as a number of departments and authorities (e.g. Alberta Environment, Alberta Agriculture and Rural Development and the Natural Resource Conservation Board) have different and sometimes conflicting directives in there legislation, regulations and guidelines. A number of interview participants noted that these conflicting messages impact the trust that people have in government. There have also been 
a number of developments in the past twenty years that have changed the political landscape of who is responsible and perhaps even accountable for some of the environmental issues [13]. These developments include the Water for Life Strategy (WFL) [14, 15], the Alberta Land-Use Framework (LUF) [16], Alberta Land Stewardship Act (ALSA) [17] and the South Saskatchewan River Basin Approved Water Management Plan (SSRB AWMP) [18].

Building on the multiple responsible authorities highlighted above, the seemingly uncoordinated introduction of these new environmental management strategies, legislation and tools have created confusion and uncertainty for water management and accountability. Presenting these pieces from earliest to latest, the 1999 Water Act [19] provides a clear regulatory framework for water management and provides clauses for additional tools. One of these tools is a water management plan approved by the Lieutenant Governor in Council. In the 2000's, after a multi-year and multi-stakeholder process was undertaken in the South Saskatchewan River Basin (SSRB), the first and only Approved Water Management Plan came into effect. The SSRB AWMP provided additional matters and factors and tools to use in water management [18] to be used in conjunction with the Water Act.

While the Water Act and SSRB AWMP set out clear accountability and responsibility for water management through the designated Director and the prescriptions of the Act and approved plans, the Alberta Water For Life Strategy (WFL), introduced in 2003 and formally recommitted to in 2008, commits to a 'shared governance' approach. In this approach to water management watershed planning and advisory councils (WPACs) were to be developed for each watershed to share in the planning and outcome delivery. There are clear discrepancies between the Water Act and the WFL around accountabilities for water management.

In 2008 the LUF and subsequent 2009 ALSA were introduced by the Government of Alberta, also providing tools, rules and responsibilities that impact water management [16, 17] and land-use planning. In 2009, mandated by ALSA and the LUF, major regional planning exercises began in northern and southern Alberta [16]. Within southern Alberta the geographic boundaries for the regional plan do not match that of the SSRB AWMP. Not only was it unclear what the direction for decision-making was on water, it was then unclear how these pieces all fit together and what rules to follow. According to the LUF and ALSA, the regional plans are to set out the highest outcomes for the region and ALSA legislation trumps all other legislation in Alberta [17]; however for many working in the areas, there is a lack of 'faith' in these large scale government exercises.

This changing government management landscape creates confusion and uncertainty that impacts the level of trust and buy-in from participants. As one interviewee noted, thinking about overall government water management, people suffered from participation fatigue and also a disappointment that after much effort and energy have gone into one process, another would suddenly come up that seemed to tackle similar work that had just been completed. These events and processes impact the perceived fit and legitimacy when new management 
options are presented as actors are uncertain about how new tools will fit into the current context, who is accountable and responsible for the results and what benefits can be gained.

\subsection{Battersea Drain Area}

The Battersea Drain Area (BDA) (Figure 1) is located in southern Alberta and is characterised by a largely Dutch, first and second generation agriculture community. Livestock production is a major component of the agricultural industry in Alberta, accounting for the largest number of cattle and calves in Canada [20]. The focus on livestock production has come at a cost. The BDA has historically had significant water quality issues that are attributable to the intensive agriculture activities in the area.

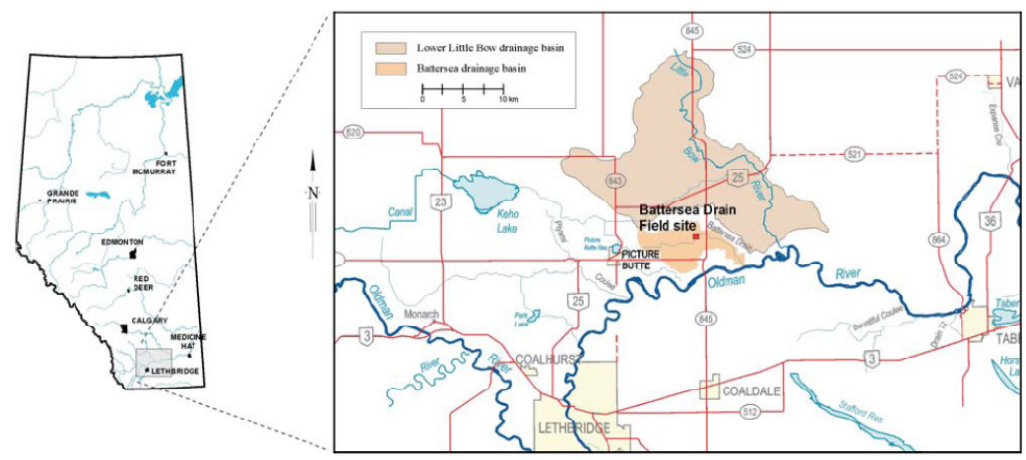

Figure 1: $\quad$ BDA in Southern Alberta. Reproduced from [21].

Water quality monitoring in tributaries of the Oldman River (within which the BDA is located) has shown total Phosphorous and total Nitrogen concentrations in excess of the Alberta Surface Water Quality Guidelines, and levels of faecal coliforms that occasionally exceed provincial guidelines for recreation and irrigation [20, 21]. Figure 2 provides a snapshot of the Water Quality Index for the BDA over a ten year period. Water quality generally degrades as water moves downstream in watersheds due to natural geological and biological processes. Pollutants from non-point sources also degrade water quality.

Within the BDA there are a number of initiatives and approaches focused on the issue of water quality. At the local drainage level, the Battersea Drain Watershed Group (BDWG) was formed. The BDWG describe themselves as a informal group of agricultural producers that live and work within the Battersea Drain Watershed that have come together with the purpose of minimizing the impacts of agricultural practices on water quality in the Battersea Drain and Oldman River [21] The BDWG's work is primarily to promote and implement Best Management Practices (BMPs) to improve water quality. There has been some success in the uptake of these BMPs; however scientific research is still ongoing and water quality issues remain [22]. 

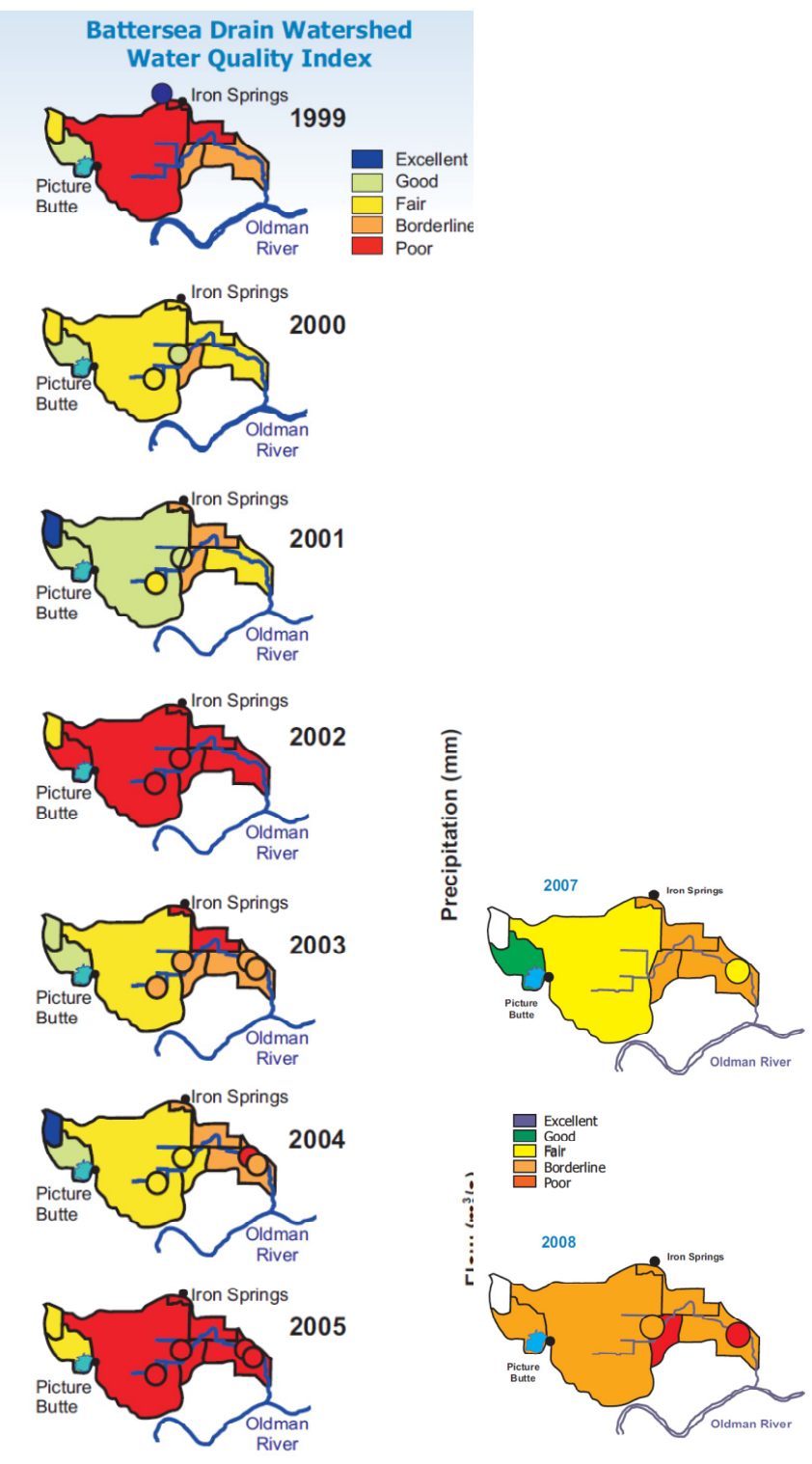

Figure 2: BDA water quality index for Battersea Drain Watershed. Reproduced from [20]. 


\section{Methods and results}

Qualitative research is inherently multi-method in focus [23]. While this paper reports on literature reviews and two sets of semi-structured interviews the analysis will be complimented by a Q sort session with key stakeholders, which is to be conducted in fall of 2011. The method used was to expose the acceptance issues associated with MBIs with stakeholders in the case study area to get their individual perspectives and perceptions for the fit, accountability and legitimacy of MBIs in that context. Q methodology further deepens this understanding as it focuses on exposing the subjective values and looking for patterns or areas of consensus around perspectives.

Two sets of semi-structured interviews were undertaken: one with MBI experts to explore the theoretical and practical incorporation of issues of fit, accountability and legitimacy in developing, implementing or analysing MBIs for environmental objectives. A second set was undertaken with local stakeholders in the case study area to explore the perspectives and value around MBIs, again focusing on the target issues of acceptance. The MBI expert interviews were carried out first in the summer and fall of 2010. The learning from these interviews was used to further focus the case study area stakeholder interviews carried out in the summer and fall of 2011. The employment of the semi-structured interview process was to understand respondents' complex perceptions without imposing any a priori categorization that might limit the field of inquiry.

The analysis of the MBI expert interviews was to manually look for themes, both those typical of economics theory and any surprises that might emerge from the responses. A similar process was used with the stakeholder interviews. NVivo will also be applied to the stakeholder interviews to look for statistical patterns and themes to support the Q sort.

There were a number of interesting and relevant themes from the two sets of interviews around the acceptance of MBIs. Both MBI experts and local stakeholders generally agreed with the definitions of accountability, legitimacy and fit. Generally there was agreement across both sets that MBIs do have a legitimate place as a tool; however there were a number of concerns about how they are used and how they fit into the context.

The MBI experts generally concluded that there are a number of constraints to MBI success including: i) an overall lack of capacity in government departments to understand, design and implement governance tools; ii) resistance due to a lack of understanding and knowledge about what the tool is and how it will impact them; and iii) lack of trust as a results of governments 'start and stop' approach to programs. These issues are similar to those raised in the literature $[24,25]$.

Importantly there was also recognition that the issues of accountability, legitimacy and fit are not explicitly incorporate into MBI design. One expert noted that in his work with government in Australia there was a melding of economic theory and 'human factors'; however the Canadian experts generally noted that there were other key factors, such as those above that were more 
prevalent in the design and implementation with governments. In analysing the interviews, it can be theorized that, at present, the human subjective values and perspectives are not explicitly incorporated, nor are they a substantial issue in the minds of many experts.

Some of the statements that emerged from the local stakeholders were consistent with the literature [26]; including: the Government of Alberta is not 'trusted' by some, which it was argued would likely impact the acceptability of an MBI. Some non-farmer interviewees noted that MBIs would be difficult to superimpose onto a system using a number of subsidies. As one interviewee noted "How can you guarantee the success of the tool when there is so much noise already". Two of the interviewees noted that if the MBI was to pay a farmer 'not to pollute' that would not be acceptable.

There were also a surprisingly strong number of interviews that all recognized that there presently is a lot of collaborative work on-going to understand and try to manage the problem. Farmers are 'at the table' working on solutions, such as the Battersea Drain Working Group, with other stakeholders in a positive and open way. Some interviewees noted that this work had built a level of trust and understanding amongst key stakeholders that had allowed for some very progressive discussion and ideas sharing. The collaborations had also allowed for a level of knowledge sharing that was important to building a more shared, if not completely common, understanding.

Another distinction that many of the stakeholders mentioned was that agriculture is not like any other industry. One of the highlighted terms was around 'part of the rural culture and fabric'. Other interviewees, farmers and non-farmers, noted that most farmers in the area act based on more than simply a purely economic motivation. While a farm is a business there are a number of other reasons why farm families are committed to 'the business'. This is also something that has been capture in the literature.

There was a general openness to MBIs as a potential tool, but there was also a hesitance that incentives are misunderstood and MBIs present uncertainty and potentially raise serious issues within the community. There was also one statement that there is a "latent and unfulfilled demand to know how landscape work". Rural communities and farmers appear to see themselves as stewards of the environment but require tools and education to go farther. More analytical work has to be done to assess these results statistically; however initial results indicate that there is an opportunity to increase the acceptability of MBIs within the BDA by understanding and incorporating some of the key areas of design, development and implementation of MBIs.

\section{Conclusions}

Within Alberta there is a push to use MBIs for environmental management; however MBIs are relatively new to the environmental management context of Alberta. While economics provide a solid framework to begin to design effective MBIs, there are missing factors. One key factor is the ability to incorporate the values and perspectives of the stakeholders that would be impacted or engaged 
with the MBI. Howard et al (2011) in this volume report some preliminary findings in this respect based on a telephone survey. This research and the forthcoming Q-method analysis will further this understanding. Additionally there are other researchers presently working on different aspects of this issue in this region [27].

The research reported in this paper has helped to expose some the themes about the acceptance of MBIs to improve water quality in the case study area. Building on the research and results, Q methodology will be employed to elicit the value orientations of the primary stakeholders in the case study area. Q method is emerging in environmental studies as a method to reveal different social perspectives that exist on an issue or topic, providing "an inductive yet systematic way of assessing the viewpoints and values of subgroups of people" [28].

Q methodology can contribute a highly useful piece of the puzzle as it explores, quantitatively and qualitatively, human subjectivity, the raw values and perspectives held by people that largely forms their judgements and decisions. The fall 2011 Q sort and subsequent analysis will be completed to reveal the key value orientations across all key stakeholders around this idea of acceptance of MBIs (fit, accountability and legitimacy). It is anticipated that these results with add a novel layer of considerations to the design and analysis of MBIs.

\section{Acknowledgements}

Funding for this research has been partially provided by the Canadian Water Network and Alberta Innovates.

\section{References}

[1] Anderies, J.M., Waler, B.H. and Kinzig, A.P., Fifteen Weddings and a Funeral: Case Studies and Resilience-based Management. Ecology and Society. 11(1), pp.21, 2006.

[2] Folke, C., Carpenter, S., Walker, B., Schffer, M., Elmqvist, T., Gunderson, L., and Holling, C.S. Regime Shifts, Resilience and Biodiversity in Ecosystem Management. Annual Review of Ecological Evolution Systems 35, pp.557-81, 2004.

[3] Cuppen, E., Breukers, S., Hisschemoller, Bergsma, E. Q Methodology to Select Participants for a Stakeholder Dialogue on Energy Options for Biomass in the Netherlands. Ecological Economics 69, pp. 579-591, et al. 2010.

[4] Oldman River Basin Water Quality Initiative. Progress summary report. 2000.

[5] Ingram, H., Water as a multi-dimensional value: implications for participation and transparency. In response to the paper by Marco Schouten and Klaas Schwartz "Water as a political good: implication for Investment” International Environmental Agreements. 6(420), p.3, 2006. 
[6] Tabera, J. David and Akgun Ilhan. Culture as Trigger for Sustainability Transition in the Water Domain: The Matisse Project and the Ebro River Basin. Paper presented at the 5th Iberian Congress on Water Management and Planning. Faro Portugal December 4-8, 2006.

[7] Ivey, J.L., de Loë, R., Kreutzwiser, R., \& Ferreyra, C. An institutional perspective on local capacity for source water protection. Geoforum, 37, pp. 944-957, 2006.

[8] North, D.C., The new institutional economics and development. Washington University, St. Louis. Retrieved at qed.econ.queensu.ca/pub /faculty/lloyd-ellis/econ835/readings/north.pdf, 1991.

[9] de Loë, R.C., Armitage, D., Plummer, R., Davidson, S. \& Moraru, L., From Government to Governance: A State-of-the-Art Review of Environmental Governance. Final Report. Prepared for Alberta Environment, Environmental Stewardship. de Loë Consulting Services Guelph, ON, 2009.

[10] Huppes, G and Simonis, U.E., Environmental policy Instruments in a News Era. Science Center Berlin. Available at http://www.wz-berlin.de/uta, 2007.

[11] Alberta Environment, Approved Water Management Plan for the South Saskatchewan River Basin in Alberta. Edmonton: Alberta Environment, 2006.

[12] Johnson, J.Y.M, Thomas, J.E., Graham, T.A., Townshend, I., Byrne, J., Selinger, L.B., \& Gannon, V.P.J. Prevalence of Escherichia coli O157:H7 and Salmonella spp. in surface waters of southern Alberta and its relation to manure sources. Canadian Journal of Microbiology, 49, pp.326-335, 2003.

[13] Poirier, Assessing Institutions For Aquatic Ecosystem Protection: A Case Study Of The Oldman River Basin, Alberta. Doctorate of Philosophy Thesis. 2008.

[14] Alberta Environment, Alberta Water for Life: Strategy for Sustainability. Online http://www.waterforlife.gov.ab.ca/docs/strategyNov03.pdf, 2003

[15] Alberta Environment, Alberta Water for Life: Strategy for Sustainability: Renewal. Online http://www.waterforlife.gov.ab.ca/.pdf 2008.

[16] Alberta Government. Alberta Land-use Framework. Online. http://www.landuse.alberta.ca/AboutLanduseFramework/Default.aspx, 2008.

[17] Alberta Government. Alberta Land Stewardship Act (ALSA). Online http://www.landuse.alberta.ca/AlbertaLandStewardshipAct/Default.aspx, 2009.

[18] Alberta Environment, Approved Water Management Plan for the South Saskatchewan River Basin in Alberta. Alberta Environment, Edmonton, Alberta, 2006.

[19] Alberta Environment, Water Act. Queen's Printer. Edmonton, Alberta.1999.

[20] Oldman River Basin Water Quality Initiative. Oldman Watershed Council. Retrieved from http://www.oldmanbasin.org/orbwqi/index.html, 2009.

[21] Olson, B.M., \& Kalischuk, A.R. (eds.). Nutrient beneficial management practices evaluation project 2007 to 2011: 2008 Progress report. Alberta 
184 Water and Society

Agriculture and Rural Development, Lethbridge, Alberta, Canada. pp. 344. 2009.

[22] Agriculture and Agri-Food Canada, Watershed Evaluation of Beneficial Management Practices (WEBs) partners, retrieved from http://www4.agr.gc.ca/AAFC-AAC/display-afficher.do?id=1228498920 881\&lang=eng, 2008.

[23] Flick, U., Qualitative Research - State of the Art. Social Science Information. 41(1), $p p, 5-24,2002$,

[24] Ivey, J.L., de Loë, R., Kreutzwiser, R., \& Ferreyra, C. An institutional perspective on local capacity for source water protection. Geoforum, 37, pp. 944-957, 2006.

[25] Bjornlund, H., Nicol, L. and Klein, K., Challenges in Implementing Economic Instruments to Manage Irrigation Water on Farms in Southern Alberta. Journal of Agricultural Water Management 92, pp.131-141, 2007.

[26] Morgenstern, R, Harrington, W, Evaluating Regulatory Impact Analyses, Discussion Papers dp-04-04, Resources for the Future. 2004.

[27] Howard, K., Xu, W., Bjornlund, H, Values and attitudes of landowners toward the supply of ecosystem services in Southern Alberta, In Progress, 2011.

[28] Vugteveen, P, Lenders, J.R., Stakeholder Value Orientations in Water Management. Society and Natural Resources, 23(1), p.3, 2010. 